\title{
Role and Philosophical Underpinnings of Cultural Performances During Academic Ceremonies: University of Education, Winneba in Perspective
}

\author{
Latipher Amma Osei ${ }^{1 *}$ Moses Adzei ${ }^{2}$ \\ 1. Department of Theatre Arts, University of Education, Winneba, P. O. Box 25, Winneba, Ghana \\ 2. Department of Music Education, University of Education, Winneba P. O. Box 25, Winneba, Ghana
}

\begin{abstract}
This paper explores the case of congregation sessions at University of Education, Winneba (UEW); discussing the role dance plays during these academic ceremonies and explore the presence of philosophical underpinnings backing the preparation of dances performed during congregations. A case study with population being the UEW community. Sampling was mainly purposive and data was gathered from three members each from the congregation planning committee, performing arts lecturers, audience and ten student performers. Data collection instruments included semi structured interviews, observations, textual and content analysis of video recording of some of the event. Discussions highlight the importance of including cultural performances during congregations and its implications on the ceremonies. Findings reveal an inalienable subculture that incorporates music and dance firmly into the life of UEW. It also highlights philosophical underpinnings backing the selection of dances performed during congregation ceremonies. The study opens up for comparative studies in other tertiary institutions in Ghana. This expression of cultural activities at tertiary level is commendable and must be encouraged to safeguard the Ghanaian cultural content.
\end{abstract}

Keywords: Congregation Ceremonies, Cultural Performance, Ghanaian Dances

DOI: $10.7176 / J P C R / 44-05$

Publication date: September 30th 2019

\section{Introduction}

Dance as an integral part of Ghanaian culture is commonplace in the literature on the culture of the Ghanaian people. This expression of culture through dance has found its way into activities of other nontraditional institutions such as corporate groups and universities. Key among the programs that showcase cultural performances during academic ceremonies include congregations and investitures. The inclusion of cultural performances in university activities is in itself a paradigm that must not elude the academic community for research purposes. Interestingly, there seems to be little or no documentation in the form of literature on such cultural performances during congregation ceremonies. The lacuna this paper seeks to fill is to add on to the growing literature on cultural activities most especially the role dance plays during such special academic ceremonies. The main questions guiding this paper are the role dance performances play during academic ceremonies at University of Education, Winneba and the availability of some philosophical underpinnings backing the preparation of dances performed during congregations.

\section{Background}

The concept of the National Theatre Movement of Ghana was based on the notion that school educated personalities become aware of traditional aesthetic forms of Ghana so as to avoid the over reliance on foreign artistic forms and rather encourage traditional activities such as dance in classroom learning (Adinku, 1994). This saw the establishment of the Institute of African Studies (IAS) in 1962 as a step in pushing for the study and development of the "creative culture" which included the performing arts (Nketia, 1976). Once the IAS was established, the government charged research fellows in the area of the performing arts most especially dance, to carry out research that would assist in the teaching of traditional dances at the then School of Music and Drama (Adinku, 1994). This was made possible under the supervision of Professors J. H. Nketia and A. M. Opoku. Their efforts began the road of dance as an integral aspect of artistic development in practical and academic activities in Ghana (Adinku, 1994).

Yartey (2009) expressed in an interview that Opoku's contributions were towards the development of new dance forms, restricted to the creative manipulation of traditional dances for theatrical performances. Some of the 
manipulations were the over repeating of some of the movements as usually seen in the communal setting. This made the dances very compact and timely. The rearrangement of traditional movement forms from their "normal" presentations gave birth to a new dance form that became appropriate for the proscenium theatre as well as academic institutions in Ghana (Adinku, 1994). The characteristics of these re-choreographed traditional dances included the inability of an audience to join in the performance except they knew the formation of the performance and the limited time for the performance of the dance on stage.

The University of Education, Winneba is a relatively young tertiary institution in Ghana. Established in 1992 as an amalgamation of seven different teacher-training and other professional colleges, the institution has grown in all fronts over the past two and a half decades. Among the several professional institutions that were merged at the time was the then National Academy of Music, which has since been converted to the Department of Music Education in the School of Creative Arts. The Music Department, which used to play a key role during such official ceremonies received a further boost with the advent of the Department of Theatre Arts in 2006 as lecturers from the twin departments prepare students to perform various dances during official programs of the university.

This paper seeks to investigate the role or significance of dance or the performing arts during university congregation ceremonies. It also seeks to address questions on the philosophical underpinnings backing the preparation of dances performed during congregations.

\section{Method}

The method of investigation, is purely qualitative in nature and employs the case study approach with the population being the UEW community. With the exception of three audience members who were randomly selected, sampling was mainly purposive and data was gathered from three members of the UEW congregation planning committee, three UEW performing art lecturers and ten UEW Theatre Arts student performers; making a total of nineteen people. Apart from members of the audience, these people were selected because of their active participation in the process of executing the performance of some cultural content during the congregation. Data was gleaned from the November session of the $23^{\text {rd }}$ congregation ceremony at UEW which lasted for six days. Data collection instruments included semi structured interviews and observations of video recording of the ceremonies. Thematic analysis was used to analyze and interpret the verbal data from the interviews and behavioral data analysis for the observations. Ethical considerations were made by seeking the consent of all the participants before engaging them. They were made aware of all recordings in the form of video or audio and were assured of their confidentiality.

\section{Discussions}

The study discusses feedback received from participants pertaining to the role dance plays during congregation ceremonies and some philosophical underpinnings backing the selection of performances during these ceremonies. Generally, all three congregation planning committee members interviewed had very little idea on the preparation of dances performed during the ceremonies. Nevertheless, they were very positive in their submission that dance played a vital role during the congregation. The audience interviewed could not hide their excitement about the nature and quality of performances and though they could not place the role dance played, they shared that the ceremonies would be "some way" (Yaa). The students interviewed shared their experiences and felt their performances were part and parcel of the ceremonies for which the ceremonies could not stand without them. The study employed thematic analysis, and for this reason, the following themes emerged and are discussed below.

\subsection{Choreographic Process}

Answers to the question of philosophical underpinnings backing the preparation of dances performed during congregations are as follows: Feedback to this question was mainly gathered from the person directly involved in the choreographic process. A performing arts lecturer who also doubled as the instructor for the preparation of dances performed during the congregation. During the semi structured interview with the instructor, she shared a number of things concerning the philosophical underpinnings backing the preparation of dances performed during congregation; and these are broken into sub themes. 


\subsection{Cultural Appropriation}

The instructor shared how dances are selected to be performed during the congregation session. "As an instructor, it is very important to take into consideration that both performers and audience are mostly Ghanaians from different regions of the country" (Ama). Since the dances are communally owned, the instructor noted that she employed the concept of cultural appropriation in the selection and execution of dances. The Urban Dictionary defines Cultural appropriation as "taking the time out to learn about different cultures and their traditions. To become more open in understanding the truth about a culture and embracing them in a respectful manner" (Urban Dictionary, n.d). "For me, I understand cultural appropriation to involve outsiders taking something from a culture other than theirs; here, the term outsiders refer to non-members of a culture while insiders are noted as members of a culture" (Ama). So if a dance is selected to be performed, there is a possibility of a performer being an insider while the others and in most cases the Instructor being outsiders to that dance. She shared that this philosophy helps to create some balance in the selection process so that selection is not skewed towards one culture.

\subsection{Social Context}

She shared that Ghanaian dance forms within the cultural context as espoused by (Adinku, 1994), centre on three main areas, which are ritual, social and recreational. She added that since the congregation ceremonies can be considered as social events, she usually works around social and recreational dances which include agbekor by the Anlo-Ewes, the dipo of the Dangme and adowa by the Akans. Each of these social dances have peculiar traditional norms that differentiate each one from the other. Selection of the performance of any of these dances during university congregations is highly dependent on the social context of the activity or its audience and its relationship with the traditional norms. Within the recreational context, dances are restricted to the entertainment needs of the users though there are different aims for the various recreational dances performed (Adinku, 1994). Some recreational dances in Ghana include gahu, sikyi, kpatsa and kpanlogo. Both social and recreational dances form part of the performances during congregation sessions at UEW. She also added that being a product of the University of Ghana, most of the dances she teaches are those taught at the University of Ghana, School of Performing Arts, which were choreographed by Nketia and Opoku.

The instructor shared that in recent times, as student population keeps increasing, congregation sessions at UEW last more than one day in which a period of three to four hours is dedicated to each day's congregation session. She used Table 1 and Table 2 to explain how dances performed during the $23^{\text {rd }}$ congregation session at the Winneba campus were selected.

During the congregation ceremony at UEW, there are three distinct activities that require the use of music and dance as the main vehicle for driving the activities namely, procession, interlude and recession and this can be seen in table 1. There are two processions during each congregation session; the first is the procession for members of Convocation and the other procession for members of the University's governing council. There is also a performance of an interlude during the congregation ceremony itself. The last but not the least is the recession, which is performed at the closure of the congregation session.

The $23^{\text {rd }}$ congregation of UEW covered six days and each day started at 9am and lasted between three to four hours each day. Table 2 outlines the graduation statistic and the various days on which specific faculties and schools had their graduation.

A glance at Table 1 indicates that the dances for procession II which is for the members of the governing council and the recession are all the Kete dance. The dance is performed by two female students and the dance is purposely chosen because it is a traditional royal dance for Akan chiefs in Ghana, specifically those whose statuses deserve being carried in palanquins (Younge, 2011). 
Table 1. Dances performed during UEW's 23rd congregation

\begin{tabular}{|l|c|c|c|c|}
\hline \multicolumn{1}{|c|}{ Days } & $\begin{array}{c}\text { Procession I } \\
\text { Convocation } \\
\text { Members }\end{array}$ & $\begin{array}{c}\text { Procession II } \\
\text { Council Members }\end{array}$ & Interlude & Recession \\
\hline Mon. 19/11/18 & Apatampa & Kete & Adzogbo & Kete \\
\hline Tue. 20/11/18 & Tora & Kete & Gahu & Kete \\
\hline Wed. 21/11/18 & Tokwe & Kete & Baamaaya & Kete \\
\hline Thur. 22/11/18 & Takai & Kete & Sikpan & Kete \\
\hline Fri. 23/11/18 & Kpatsa & Kete & Boboobo & Kete \\
\hline Sat. 24/11/18 & Agbeko & Kete & Dance Mali & Kete \\
\hline
\end{tabular}

The governing council, whose members are perceived to be the elders of the university community as pertains in most Ghanaian societies, must be accorded the maximum respect during such important occasions. They are likened to chiefs of high statuses and for this reason, Kete is performed for them to give them that reverence. The recession is done in a hierarchy. The council members are ushered out first

followed by members of convocation and then the students and their guests. For this reason, there is only one recession dance which is the kete and it is led by the council members.

The decision for the dances performed during procession I which is for convocation members and the interludes are more flexible and give room for the performance of both social and recreational dance forms from across Ghana. The movements selected for the procession are those of travelling or locomotion. This is meant to make the procession smooth with less or no in-place movements that would hold up the procession. The Interlude is the dance performed during the congregation ceremony and it is usually slotted after the Vice Chancellor has given his speech. All the dances performed during the first three days were selected on the assumption that all the faculties involved had their campuses based at the main campus which was Winneba yet the guests cut across the lengths and breadths of Ghana. The various faculties and schools can be seen in Table 2.

Table 2. The $23^{\text {rd }}$ Congregation Winneba Campus $19^{\text {th }}-24^{\text {th }}$ November 2018

\begin{tabular}{|l|l|l|}
\hline Days & Faculties / Schools & \multirow{2}{*}{ Campus / Study Centers } \\
\hline Mon. 19/11/18 & Faculty of Science Education & \multicolumn{1}{|c|}{ Winneba } \\
\cline { 2 - 2 } & School of Business & \\
\hline Tue. 20/11/18 & Faculty of Educational Studies & \\
\cline { 1 - 2 } Wed. 21/11/18 & $\begin{array}{l}\text { Faculty of Ghanaian Languages } \\
\text { Education }\end{array}$ & \\
\cline { 2 - 2 } & Faculty of Social Science Education & \\
\hline Thur. 22/11/18 & $\begin{array}{l}\text { Institute for Distance and e-Learning } \\
\text { (IDeL) }\end{array}$ & $\begin{array}{l}\text { Study Centers } \\
\text { Accra Academy, Accra Attraco, Accra Wesley } \\
\text { Girls, Asamankese, Assin Foso, Axim, Cape } \\
\text { Coast, Dambai, Hohoe }\end{array}$ \\
\hline \multirow{3}{*}{ Fri. 23/11/18 } & $\begin{array}{l}\text { Institute for Distance and e-Learning } \\
\text { (IDeL) }\end{array}$ & $\begin{array}{l}\text { Study Centers } \\
\text { Denu, Ho, Koforidua, Odumasi-Krobo, Sekondi, } \\
\text { Sogakope, Tarkwa, Tema, Winneba }\end{array}$ \\
\hline \multirow{3}{*}{ Sat. 24/11/18 } & $\begin{array}{l}\text { Faculty of Foreign Languages } \\
\text { Education and Communication }\end{array}$ \\
\cline { 2 - 2 } & School of Creative Arts & \\
\hline
\end{tabular}


On the first day of the congregation which was Monday the $19^{\text {th }}$ of November, as seen on table 2, UEW graduated students from the Faculty of Science Education and the School of Business. Since the faculty is situated at the main campus which is Winneba, the instructor said she decided to have the apatampa dance for procession I to welcome all the invited guests, parents and families of graduating students to Winneba. According to Ebeli (2011), Apatampa is an ensemble belonging to the Fantis and has two mythical historical accounts for its origin. "Although there are variants in both accounts, they are directed to the attainment of a common result, which was the elimination of the monster or river god" (34). According to the instructor, the reason for selecting the Apatampa to be performed on the first day of the congregation, was to serve a metaphoric significance in the lives of the graduating students. They have been able to overcome all the challenges (monsters) associated with student life and have emerged victorious.

On that same day, the interlude performed was the Adzogbo. Adzogbo is a religious ritual dance that was once performed prior to going into battle (Younge, 2011). The instructor indicated that though the dance was mainly performed in the night to summon the warriors to commune with the gods before going to war, it was selected as a dance to be performed on the first day of the congregation to symbolize a spiritual connotation of communing with the almighty God, Allah and gods for the success of the whole ceremony.

On the second day, Tuesday $20^{\text {th }}$ November, the university graduated students from the Faculty of Educational Studies and the tora dance was performed for procession I. "Tora evolved from the Takai musical type for men hence it has almost the same rhythmic features" (Ebeli, 2011, 57). It can be described as a dance reserved for the Dagomba royals. The instructor added that it was on the basis of its royal nature that the dance was selected to be performed for the procession of members of convocation who are seen or revered as sub-elders in the university community.

On that same day, Gahu was performed during the interlude session. Gahu is also a recreational dance performed by the southern ewes and its name is a combination of two words, 'ga' meaning money or greatness and 'hu' meaning drum or dance drumming type (Ebeli, 2011). Here the dance was selected to depict the economic significance of education and how a good investment in a child's education will yield results of success in life, this the instructor indicated.

On the third day, Wednesday $21^{\text {st }}$ November, the Faculty of Ghanaian Languages and Faculty of Social Science Education were graduated and Tokwe was performed for the procession I. Tokwe is a dance performed by young women who have come of age and are presented to the local community for the prospect of marriage to the most eligible young man (Palmer 2012). A similar though or idea goes into selecting this dance to be performed. The graduation ceremony is a time to present students who have completed their education in an area of study, it is also the ceremony presenting them to the world of work, this the instructor noted.

The interlude for that day was Baamaaya. Baamaaya is one of the most commonly performed dances during public events in the Northern region of Ghana. The dance is performed in remembrance of a severe drought that befell the Dagbon land, which resulted in the consultation of the gods (Ayettey, 2012). The oracle instructed that for the drought to end, the men had to appease the gods by wearing women's apparel; it was believed that the prayers of women usually got quicker response than those of men (Gyesi, 2015). The instructor added that the main reason for selecting this dance to be performed is basically for its aesthetic purposes of seeing men dressed as women.

The fourth and fifth days had the Institute for Distance Education and e-Learning (IDeL). Since the Institute is of a distant learning nature, it has smaller units of study centers across the country. During such days the instructor randomly selects any of the study center's and if possible selects a dance from that area. So for the fourth day, the Takai was performed for procession I and the Sikpan was performed for the interlude. The Takai dance, which is performed during the Damba festival of the Dagomba people of Ghana is one of the most respected and visible cultural practices among the Dagomba community. The festival is held in commemoration of the birth of the holy prophet, Mohammed. The dance is a blend of Islamic religious influences, reflected both in the costume worn by the dancers and in the actual movements of the dance. Today, the original commemorative function of the Takai has expanded to cover funerals, weddings and other special occasions (National Commission on Culture, 2009). The Sikpan is a name coined out of a medley of two dances which are Sikyi and Kpanlogo. Sikyi is an Akan recreational dance-drumming performed by the youth and it is believed that the dance is associated with flirtatious movements to suggest courtship and marriage (Younge, 2011). Kpanlogo is a musical type among the Ga people. Though the dance was not accepted by the elders from the start, because of its profane nature, it was rather patronized and embraced by the youth and is performed for recreation and entertainment (Ebeli, 2011; Younge, 2011). The reasons for selection of these dances was purely for entertainment. The Takayi was to 
welcome the Dambai people, the sikyi to welcome the Akan people and the kpanlogo to welcome the Ga people.

On the fifth day, students from other study centres of IDel were graduated and for procession I, the Kpatsa was performed to welcome the Ga Adangme people. The interlude was the Boboobo to welcome the Ewe people. Kpatsa is a recreational dance among the Adangme of the Greater Accra region of Ghana that is basically for entertainment. It is on this basis that the dance is performed to entertain the students from the Ga Adangme study center. Boboobo which literally means bending down, is also a recreational dance predominantly performed by the people of Northern Volta (Ebeli, 2011). Its elements of military music due to the use of a bugle as one of its instruments makes it an enjoyable dance for both young and old. Again it is against the backdrop of its recreational nature that the Boboobo is performed to entertain the guests on that day.

The final day saw the graduation of students of the School of graduate Studies, the Faculty of Foreign Languages Education and Communication and last but not the least, the School of Creative Arts. On this day slow agbeko was performed for procession I, while the Dance Mali was performed as an interlude. The Slow agbeko is a slower version of the main Atsiagbeko dance. In the days of old it was performed by brave men after war to demonstrate their deeds of valor on the battlefield to those at home. The instructor added that the selection of this dance on the final day was meant to symbolize the end of all the hardships students had to face in their studies and coming out victorious. The final day saw the graduation of students of the School of Creative Arts and since performers are affiliated to this school, the instructor selected the performance of Dance Mali as the interlude. Dance Mali is choreographed dance piece that incorporates dance movements from a variety of African dances. The beauty of this dance resides in the dexterity of movement execution. The selection of this dance is mainly for entertainment and exhibition of creativity.

\subsection{Color and National Identity}

Feedback from interviews of the member of the congregation planning committee indicated the existence of a document on UEW academic ceremonies. This document spelt out the nature and form most academic ceremonies should take. This document clearly highlighted music and dance art forms as integral components of the University's ceremonies. It was also identified that, academic ceremonies at UEW such as congregations always had to begin and end with processions. "Appropriate music provided by the drumming, dancing and playing of local horns, gives the marchers a stately nature and affords the audience time to savor the meaning of the day and its color" (University of Education, 2012, 7).

From the perspective of the committee members, responses gathered for the above question indicated that the reasons for including cultural performances during congregations was first and foremost to project the Ghanaian identity and then serve as a form of relaxation and entertainment for the invited audience as well as add color to the ceremonies.

For the question of how different the ceremony would be if there were no cultural art forms, responses gathered from committee members, performing art lecturers, students and audience indicated varied answers of the ceremony being dull, boring, monotonous and flat.

The best moments for me... are when the performances are going on; it's... [makes hand gestures] I don't know how to put it... it's so colorful and awakening (Akua)

\subsection{Differences and Similarities}

For the question which was investigating the extent to which the cultural performances during UEW congregations differ from other universities, again data was gleaned from members of the committee, performing art lecturers, student performers and audience. The following are submissions by a committee member, an audience and a performing art lecturer:

I once witnessed a congregation session in another university here in Ghana, I didn't know the ceremony had started, all I saw was that members of convocation and council were passing in a file; It was so different from what I was used to. UEW congregations are very dramatic, drums, music and dance alert people of some happening. (Serwaa)

I have been to two other Universities... That is the University of Cape Coast and err!! University of Ghana, Legon and they also had such performances... frankly I don't see any significant difference. For me they are all beautiful to watch. (David)

Yes! Unlike UEW and and University of Cape Coast where performances are by students, University of 
Ghana congregation performances are by the resident theatre company who are professional dancers. (Isaac)

All the above views from the audience, members of the congregation planning committee, and performing art students and lecturers, go a long way to indicate that people love this aspect of performance during congregation ceremonies.

\section{Conclusion}

In a nutshell, this paper tried to discuss the role dance plays during UEW congregation ceremonies. Dance performances during congregation sessions at the University of Education, Winneba (UEW), like any socio-cultural setting, plays vital roles that back the congregation sessions. The congregation is made up of revered personalities who assist in the higher purpose of conferring degrees on graduants. The role of the performance of cultural music and dance during congregation sessions give the ceremony that ambiance of typical African durbars where elders and custodians of the land are ushered into the gathering of the community with rich traditional music and dance amidst interludes of cultural performances. University of Education, Winneba as an academic institution has over the years not only showcased such rich Ghanaian culture during its congregations but has also used the occasion to communicate multidimensional roles of these cultural performances. An analysis of the various dances which constitute a cocktail of cultural music and dance during a highly academic event is a demonstration of an integrated culture of institutional, material and psychological culture. It is hoped that the university would sustain this practice and also promote a culture of innovation in respect of its programs thereby promoting a truly holistic center of training for Africa's future transformation. The study equally opens up the space for comparative scholarships in other tertiary institutions in Ghana.

\section{References}

Adinku, W.O. (1994). African dance education in Ghana. Accra: Ghana Universities Press. 1-19

Ayettey, B.O. (2012). "The baamaya dance suite, a tale of Dagbamba." Institute of African Studies Research Review 27(2): 61-74.

Ebeli, E. (2011). Profiles of selected traditional dances of Ghana. Accra: Sundel Services. 1-52

Gyesi, Z.K. (2015). "The untold story behind the baamaya dance." Ghraphic Online. http://www.graphic.com.gh (accessed Feb. 24, 2018).

Nketia, J.H. (1976). "The role of university in cultural development in Africa." Legon: Institute of African Studies, University of Ghana. 1-3.

Palmer, J. (2012). Introduction to African dance. https://www.roh.org.uk (accessed Nov 27, 2018).

Spencer, P. (1986). Society and dance: the social anthropology of process and performance. Cambridge: Cambridge University Press.

University of Education. (2012). "Hand book on academic ceremonies." Edited by Mawutor Avoke, Richard Awuah, S. M. Quartey, C. Okae-Anti and Steve Kamassah. Winneba: Publication Unite-UEW. 1-7.

Urban Dictionary. (n.d). https://www.urbandictionary.com/define.php?term=Cultural\%20Appropriation

Younge, P.Y. (2011). Music and dance traditions of Ghana: History, performance and teaching. North Carolina: McFarland \& Company, Inc. 33-198 